\title{
Visualizing ideas-heard of C-map
}

\section{Rajarajeswari Neethiselvan*, Suguna Anbalagan, Surekha Anbalagan, Seetharaman Narayanan}

\begin{abstract}
Department of Community Medicine, Mahatma Gandhi Medical College and Research Institute, Puducherry, India
\end{abstract}
Received: 24 April 2019

Accepted: 08 June 2019

\section{*Correspondence:}

Dr. Rajarajeswari Neethiselvan,

E-mail: rajiselvan001@gmail.com

Copyright: (c) the author(s), publisher and licensee Medip Academy. This is an open-access article distributed under the terms of the Creative Commons Attribution Non-Commercial License, which permits unrestricted non-commercial use, distribution, and reproduction in any medium, provided the original work is properly cited.

\begin{abstract}
Communication and interaction between teachers and students always plays a vital role in building a sound educational system where learning becomes an experience. Further enhancement of this learning and understanding of the subject can be supported and secured by a process of conceptual mapping. Conceptual mapping is a step-wise process which includes text filling, relational predicates (understanding) and finally constructing the map. It is a technical tool which is easily accessible and economical in its time use. The idea of using the concept map is still in the primitive level and more emphasis has to be made in this area to use it to its full potential in the academic field.
\end{abstract}

Keywords: Concept map, Visualizing ideas

\section{INTRODUCTION}

Within the developing educational system learning becomes a communicative process between the teacher and the student. Approaches in learning are expected to create advanced cognitive skills such as construction, analysis as well as meta-cognitive skills among students at higher education. In particular, university students are expected to practice higher order skills such as synthesis, analysis and meta-cognitive skills. ${ }^{1}$ Meta-cognitive skills are visualization techniques that make the flow of thinking more visible and allow learners to express their understanding in a graphical model. ${ }^{2,3}$ One of the metacognitive techniques is the conceptual map in which students draw their understanding in an explicit graphical map.

Concept maps were first developed at Cornell University in 1972 by Novak and his research team. A concept map or conceptual diagram that represents the relationship between concepts. ${ }^{4}$ This graphical tool emphasis the learners to understand the complex information in precise way. Learners will pursue the acquisition of additional information using logical reasoning to illustrate the links between concepts.

\section{STEPS TO DEVELOP A CONCEPTUAL MAP}

To develop a concept map learner have to

- $\quad$ identify the main domain of the material.

- identify related words and create sub concept as clusters.

- arrange the sub concept at the bottom and main concept at the top of the page.

- create a new node that names the sub concepts and use links to form the preliminary map.

- $\quad$ name the links.

- identify as many cross concepts and create a link between them.

The domain knowledge should be more realistic and captive and helps the individual learner dynamically taking into account his/her learning need and his/her different learning pace. 
One of the basic conceptual maps is termed hierarchical that recognizes the concept and attributes in a hierarchical structure. Concepts in a hierarchical structure have communication from top-to-bottom and side-to-side relations. ${ }^{5}$ Once the learner completes in developing the map, it should be revised finally. Concepts re-positioned in ways that lend to be more clear and effective and final map is prepared.

\section{Example}

Figure 1 illustrates about the challenges faced during motherhood period, the experiences that mothers face in their journey through motherhood is bound to be influenced by a multitude of factors- their personal health status, emotional, their outlooks and beliefs, family support systems and the social milieu the women live in. Motherhood plays a vital role in women's life.

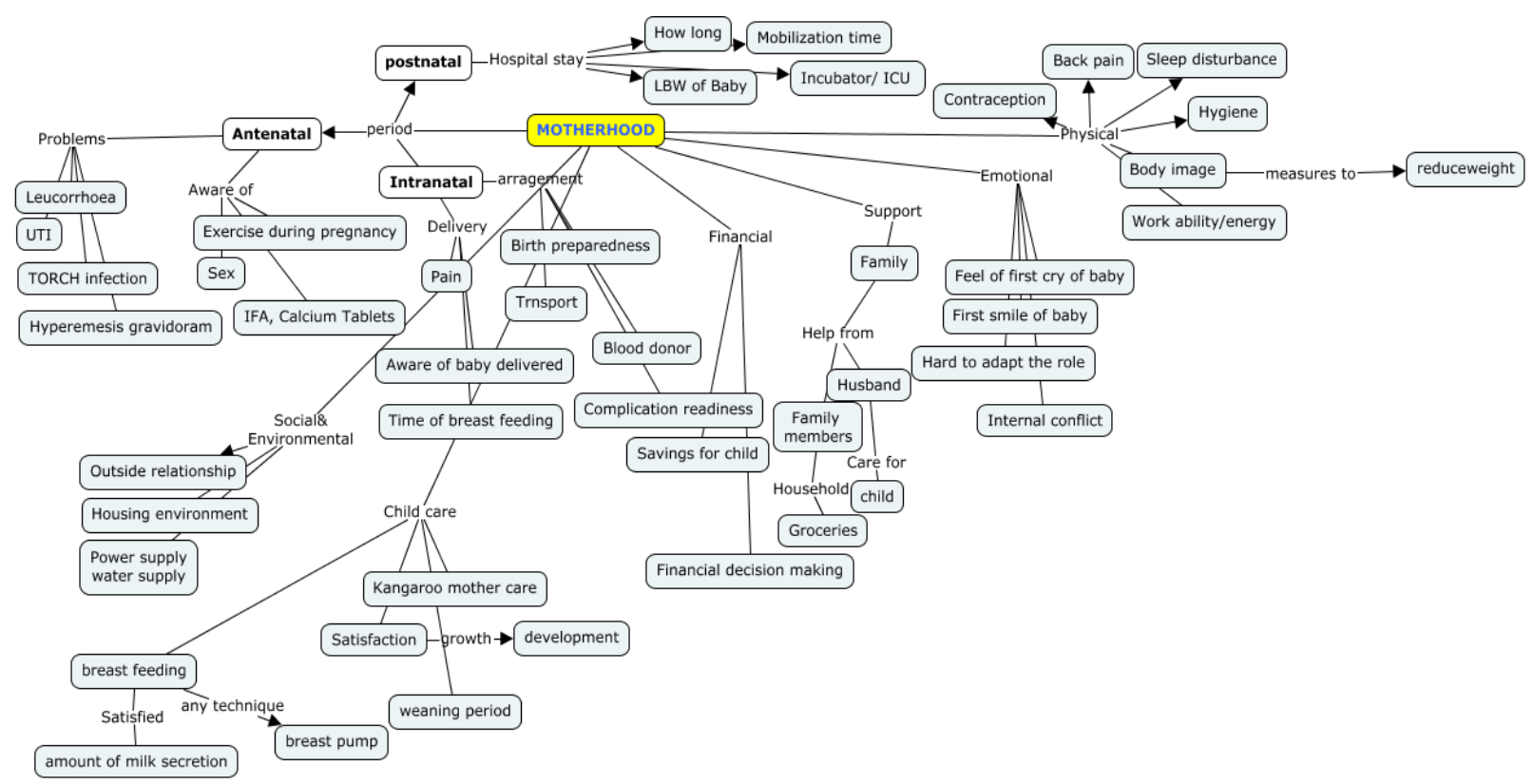

Figure 1: Challenges faced by the mothers during their motherhood period.

\section{MAP TOOL}

C map tool (software) was developed at the Institute for Human and Machine Cognition. The software can be accessed and availed easily. The digital tool allows the user to link resources such as images, graphs, videos, charts, texts can be added, change of font size and style and add colours to their map. The tool allows educators to observe a concept from students' perspective and track students' learning over time. The software aids the learners to develop a whole concept from a single idea which gives them a glance/overview of the topic.

\section{Benefits of conceptual map}

- Easy way of "Note taking" by the learners/students.

- Helps the students to understand the complex information in a precise form.

- $\quad$ Easy memory recall.

- Helps to clarify and structure the ideas.

- $\quad$ Probing the students to think creatively.

Helps students evaluate assumptions.

\section{CONCLUSION}

Concept maps are constructed to reflect organization of the declarative memory system, they facilitate sensemaking and meaningful learning of the learners who make concept maps and those who use them. Concept maps are more free form, as multiple nodes or clusters created. However, mind maps facilitate the learners to think about a single topic and is often restricted to tree structure.

To conclude, valuable evidence for establishing conceptual map as a continuous teaching strategy in an educational institute. Concept map helps in monitoring learners to provide instructors feedback for improving learners understanding as well as instructor's expectation.

\section{ACKNOWLEDGEMENTS}

We would like to thank Department of Community Medicine, Mahatma Gandhi Medical College and Research Institute, Puducherry, India.

\section{Funding: No funding sources \\ Conflict of interest: None declared \\ Ethical approval: Not required}




\section{REFERENCES}

1. Villalon J, Calvo RA. Concept maps as cognitive visualizations of writing assignments. J Educ Techno Soc. 2011;14(3):16.

2. Jacobson MJ. Cognitive visualisations and the design of learning technologies. Int. J. Learn. Technol. 2004;1(1):40-62.

3. Collins C, Carpendale S, Penn G. Docuburst: visualizing document content using language structure. In: Computer graphics forum. Oxford, UK: Blackwell Publishing Ltd; 2009: 1039-1046.
4. Hager PJ, Scheiber HJ, Corbin NC. Designing and delivering: scientific, technical, and managerial presentations. John Wiley \& Sons; 1997.

5. Chang KE, Sung YT, Chen ID. The effect of concept mapping to enhance text comprehension and summarization. J Exp Educ. 2002;71(1):5-23.

Cite this article as: Neethiselvan R, Anbalagan $\mathrm{S}$, Anbalagan S, Narayanan S. Visualizing ideas-heard of C-map. Int J Community Med Public Health 2019;6:3165-7. 